http://dx.doi.org/10.30681/23588403v11i01107122

\title{
A IMPORTÂNCIA DA HABILIDADE DE LEITURA NO PROCESSO DE APRENDIZAGEM DE LÍNGUA INGLESA NO CONTEXTO DA EDUCAÇÃO BÁSICA
}

\author{
Data de recebimento: 03/11/2017
}

Aceite: 16/01/2018

Camila Souza de ANDRADE (UFF) ${ }^{1}$

\begin{abstract}
Resumo: O ensino de língua inglesa no espaço escolar tem sido alvo de muito desprestígio, contribuindo para que alunos e professores acreditem que seja impossível aprender inglês na escola. Com base nos estudos de Moita Lopes (1996) e Carmagnani (1987) este artigo destaca a importância do ensino da habilidade de leitura, pois, assim, o ensino de língua inglesa seria mais atrativo e dinâmico. Dentro dessa proposta, consideram-se as estratégias de leitura relevantes para o processo de ensino-aprendizagem de leitura em língua inglesa. Para a realização desta pesquisa foi selecionado um livro didático destinado a alunos do Ensino Médio que é utilizado em escolas públicas estaduais do Rio de Janeiro. Os dados foram obtidos através da análise das atividades de leitura propostas pelo livro High up. Os dados levantados evidenciam que algumas atividades de leitura não têm por objetivo trabalhar a habilidade de leitura em si, mas, sim, outras habilidades linguísticas. Em nossa conclusão, evidenciamos que é importante ensinar as estratégias de leitura no processo de ensino de língua inglesa.
\end{abstract}

Palavras-Chave: Ensino Médio. Estratégias de leitura. Língua Inglesa. Leitura.

\begin{abstract}
The teaching of English in the school space has been very discouraged, helping students and teachers to believe that it is impossible to learn English in school. Based on the studies of Moita Lopes (1996) and Carmagnani (1987), this paper emphasizes the importance of teaching reading ability, therefore, English language teaching would be more attractive and dynamic. Within this proposal, we consider the reading strategies relevant to the teachinglearning process of reading in English. For the accomplishment of this research was selected a didactic book destined to students of the High School that is used in state public schools of Rio de Janeiro. The data were obtained through the analysis of the reading activities proposed by the book High up. The data shows that some reading activities are not intended to work the reading ability itself, but rather other language abilities. In our conclusion, we have shown that it is important to teach reading strategies in the English language teaching process.
\end{abstract}

Keywords: High School. Reading strategies. English language. Reading.

Introdução

\footnotetext{
${ }^{1}$ Mestranda do Programa de Pós-graduação em Estudos de Linguagem da Universidade Federal Fluminense. Especialista em Leitura e Produção de Textos pela Universidade Federal Fluminense. Niterói/ RJ/ Brasil. E-mail: csaletras@ gmail.com. Este artigo é um recorte de monografia de conclusão do curso de Especialização em Leitura e Produção de Textos, apresentada ao Programa de Pós-graduação em Letras da Universidade Federal Fluminense, sob orientação da $\operatorname{Prof}^{\mathrm{a}}$ Dr $^{\mathrm{a}}$ Sonia Monnerat.
} 


\section{Revista de Estudos Acadêmicos de Letras}

É indiscutível que o aprendizado da língua inglesa é de suma importância devido ao seu status de língua de comunicação global. A língua inglesa não está relacionada apenas a aspectos profissionais, mas também, a vida pessoal, visto que estamos em constante contato com a língua inglesa no nosso cotidiano, seja através de produtos internacionais, músicas, filmes, séries, rede sociais e etc, a língua inglesa está presente em todos os lugares ao redor do mundo (BRETON,2005).

De acordo com os Parâmetros Curriculares Nacionais do Ensino Médio, as aulas de línguas estrangeiras no espaço escolar têm sido focadas em conteúdos gramaticais, estruturais e distantes da realidade do aluno. Com as aulas seguindo esse modelo, os discentes ficam desmotivados em aprender a língua estrangeira na escola e passam acreditar que seja impossível aprender um idioma no contexto escolar.

Diante desse cenário e fundamentado nos estudos de Carmagnani (1987) e Moita Lopes (1996), esse artigo aborda a importância do ensino da habilidade de leitura para um ensino eficiente e atrativo. Dentro dessa proposta, consideramos as estratégias de leitura relevantes para o processo de ensino-aprendizagem de leitura em língua inglesa. Para esse estudo analisamos as propostas de atividades de leituras do livro didático High up e verificamos a presença ou ausência de estratégias de leitura nas atividades e se as atividades têm foco na habilidade de leitura ou se exploram outras habilidades.

\section{A leitura, o ensino de leitura e as estratégias de leitura: um breve panorama teórico}

No nosso cotidiano, estamos cercados de várias atividades, e a leitura é uma dessas. Se refletirmos sobre todas as possibilidades de leitura com que estamos em contato diariamente, chegamos à conclusão de que não passamos um dia sequer sem ler alguma coisa. Lemos todos os dias e várias vezes ao dia sem nem ao menos perceber que estamos em contato direto com a leitura através de mensagens de texto, WhatsApp, redes sociais, panfletos, jornais, textos publicitários, entre outros. Isso sem mencionar as leituras que selecionamos para o nosso momento de estudo e/ou entretenimento. Mas afinal o que é leitura? O que é ler?

A leitura assume diferentes concepções. De acordo com os estudos de Jouve (2002), “a leitura é uma atividade complexa, plural, que se desenvolve em várias direções”. Para Goodman (1998, p.12) a leitura é "um processo psicolinguístico que começa com uma representação linguística codificada por um escritor e termina com o significado que o leitor 
constrói". Enquanto que para Farrel (2003, p.2) a "leitura é o processo de construção de significado através da interação dinâmica entre o conhecimento existente do leitor, a informação sugerida pela linguagem escrita, e o contexto da situação de leitura.” A partir dessas afirmações, podemos constatar que a leitura é uma atividade que envolve muito mais do que apenas a decodificação.

Ao ler estamos nos conectando com o outro, visto que ler sempre pressupõe um indivíduo que, ao falar ou escrever, constrói seu discurso em função de um ouvinte ou leitor. Abordando também a temática, Nuttall (1996) afirma que lemos porque buscamos algo de determinado texto. Buscamos informações, ideias, fatos, entre outros. Com base nessa informação, podemos constatar que a leitura está ligada ao significado, isto é, como se alcança o significado a partir da interação entre o autor do texto e o leitor.

Reforçando essa ideia, Wallace (1992) afirma que nós usamos a leitura para um propósito, e que ela só faz sentindo dentro de um contexto. A autora certifica também que ler é um exercício que envolve interpretação, isto é, reagir ao texto como um ato comunicativo. Assim, podemos afirmar que o escritor tem uma intenção comunicativa e que o leitor tem o propósito de tentar entender essa mensagem.

É importante ressaltar que, quando o indivíduo inicia seu processo de leitura, ele ativa alguns conhecimentos que ele já possui. Nesse sentido, Paulo Freire (2006, p.11) afirma que "a leitura do mundo precede a leitura da palavra", ou seja, as pessoas, através da exposição à própria vida, leem o mundo à sua volta. E pelo intermédio da leitura de mundo que nós amadurecemos nossos pensamentos, e, com isso, assimilamos melhor a leitura, agregando assim significados ao texto. Para o autor, desde pequeno se aprende a compreender o mundo ao nosso redor. É por esse motivo que, antes de aprender a ler e a escrever palavras e sentenças, lemos o mundo à nossa volta. Paralelamente a isso, Kleiman (1995, p.13) afirma que:

a compreensão de um texto é um processo que se caracteriza pela utilização de conhecimento prévio: o leitor utiliza na leitura o que ele já sabe, o conhecimento adquirido ao longo de sua vida. É mediante a interação de diversos níveis de conhecimento, como o conhecimento linguístico, o textual, o conhecimento de mundo, que o leitor consegue construir o sentido do texto. E porque o leitor utiliza justamente diversos níveis de conhecimento que interagem entre si, a leitura é considerada um processo interativo.

Seguindo essa mesma diretriz, Garcez (2001) assegura que a leitura é um processo complexo e abrangente de decodificação e de compreensão do mundo. O autor salienta também 
que a leitura não envolve apenas os elementos da linguagem, mas os da experiência de vida de cada pessoa. Com isso, podemos constatar que, para ler, não basta apenas saber decodificar a língua, mas, sim, ter outros conhecimentos que não são apenas linguísticos.

No que tange às questões sobre os conhecimentos para realizar uma leitura eficiente, Kleiman (1995) afirma que "o conhecimento linguístico desempenha um papel central no processamento do texto". Isto é, ao passo que as palavras são percebidas pela nossa mente, ela constrói significados; e um dos primeiros passos é agrupar frases com base no conhecimento gramatical que temos. Expandindo um pouco mais a temática, a autora postula que, quanto mais conhecimento textual o leitor tiver, maior será a sua exposição a todo tipo de texto, e mais fácil será a sua compreensão. Isso se deve ao fato de que o conhecimento de estruturas textuais e de tipos de discursos determinará as expectativas do leitor, sendo que estas exercem um papel considerável na compreensão. A autora afirma também que tanto o conhecimento linguístico como o conhecimento textual fazem parte do conhecimento prévio e que ambos devem ser utilizados na leitura através da inferência.

O conhecimento de mundo ou o conhecimento enciclopédico é importante para o processo de leitura. Segundo Kleiman (1995), esse conhecimento pode ser adquirido tanto formalmente como informalmente. A autora destaca que o leitor pode não compreender o texto devido a falhas no conhecimento de mundo e que este conhecimento é relevante para a leitura e deve estar ativado. O conhecimento de mundo não pode estar perdido no fundo de nossa memória. Como exemplos de conhecimento de mundo, a autora cita: "o gato é mamífero" e também menciona os que são adquiridos socialmente, por exemplo, sobre o que está envolvido em ir ao médico. Por fim, Kleiman (1995, p.26) afirma que:

o conhecimento linguístico, o conhecimento textual, o conhecimento de mundo devem ser ativados durante a leitura para poder chegar ao momento da compreensão, momento esse que passa desapercebido, em que as partes discretas se juntam para fazer um significado. O mero passar de olhos pela linha não é leitura, pois leitura implica uma atividade de procura por parte do leitor, no seu passado, de lembranças e conhecimentos, daqueles que são relevantes para a compreensão de um texto que fornece pistas e sugere caminhos, mas que certamente não explicita tudo o que seria possível explicitar.

No que concerne ao ensino de língua inglesa no espaço escolar, os Parâmetros Curriculares Nacionais do Ensino Médio (2000, p.25) afirmam que ao invés de capacitar o aluno 
a falar, ler, escrever e compreender um novo idioma, as aulas de línguas estrangeiras no âmbito escolar assumiram uma feição monótona e repetitiva, muitas vezes, desmotivando alunos e professores; ao mesmo tempo em que se desvalorizam conteúdos que são relevantes para a formação dos estudantes. Com isso, o ensino de línguas estrangeiras nas escolas precisa ser repensado de modo a possibilitar, como sugerem os PCN (2000), que os alunos tenham realmente maior capacidade de reflexão:

Ao conhecer outra(s) cultura(s), outra(s) forma(s) de encarar a realidade, os alunos passam a refletir, também, muito mais sobre a sua própria cultura e ampliam a sua capacidade de analisar o seu entorno social com maior profundidade, tendo melhores condições de estabelecer vínculos, semelhanças e contrastes entre a sua forma de ser, agir, pensar e sentir e a de outros povos, enriquecendo a sua formação. (BRASIL, 2000, p.30).

O ensino de língua estrangeira, no caso da língua inglesa, com a habilidade de leitura trabalhada de maneira mais ativa, isto é, explorando as estratégias de leitura e os conhecimentos de mundo dos alunos, seria uma alternativa para motivar e melhorar o processo de ensino e aprendizagem de língua inglesa no espaço escolar.

A respeito do ensino da habilidade de leitura, Carmagnani (1987) destaca que o ensino focado em leitura poderia contribuir para o processo de ensino-aprendizagem, pois o aluno teria a oportunidade de ser mais ativo na aula de língua estrangeira ao passo que estaria colecionando informações de maneira ativa e interpretando o texto com base no seu conhecimento de mundo. Ademais, a autora salienta também que, dessa maneira, a aula de língua estrangeira deixa de ser um espaço apenas para os que têm aptidão no idioma ou os que fazem cursos paralelos.

Destacando o benefício do ensino da habilidade de leitura, Moita Lopes (1996) ressalta que através da leitura em língua estrangeira o aluno é exposto a visões diferentes do mundo e de sua própria cultura. Além disso, o autor menciona que a aprendizagem da leitura em língua estrangeira fornece ao estudante um base discursiva por intermédio do seu engajamento negociação do significado via discurso escrito que poderá ser ampliada, posteriormente, através do discurso oral.

No que concerne aos estágios de leitura como objetivo pedagógico, podemos citar três níveis de leitura: pré-leitura, leitura (superficial e profunda) e pós-leitura. Amorim (1997) afirma que a primeira fase, pré-leitura, tem por objetivo ativar o conhecimento prévio do estudante acerca do assunto do texto a ser lido. A segunda fase refere-se à leitura propriamente dita, podendo ser uma leitura superficial ou uma leitura profunda. Na leitura superficial, o aluno deverá levantar hipóteses e verificá-las com o propósito de obter uma compreensão geral do 
texto. Já na leitura profunda, espera-se que o aluno seja capaz de ter uma compreensão detalhada do texto. E, por último, temos a pós-leitura, que se caracteriza pela apresentação de pontos acerca do tema do texto para promover uma discussão em sala. Nesta última fase, esperase que os estudantes sejam capazes de argumentar/ contra argumentar sobre o texto lido.

Cabe aqui destacar que esses estágios de leitura são de cunho pedagógico e são altamente pertinentes, visto que colaboram para a construção do sentido do texto. Como mencionado anteriormente, a leitura é um processo no qual o leitor constrói o significado através do texto, ou seja, leitores diferentes podem ter interpretações diversas de um mesmo texto. Esse processo é individual, já que cada leitor constrói o significado de maneira singular. Levando isso em consideração, Kleiman (1989, p.151-152) afirma que:

ensinar a ler com compreensão não implica em impor uma leitura única, a do professor ou especialista, como a leitura do texto. Ensinar a ler, é criar uma atitude de expectativa prévia com relação ao conteúdo referencial do texto, isto é, mostrar à criança que quanto mais ela previr o conteúdo maior será sua compreensão; é ensinar a criança a se autoavaliar constantemente durante o processo para detectar quando perdeu o fio; é ensinar a utilização de múltiplas fontes de conhecimento - linguísticas, discursivas, enciclopédicas - para resolver falhas momentâneas no processo.

No que concerne aos modelos de leitura, Kato (1999) postula que existem dois tipos básicos de processamento de informação: o bottom-up (ascendente) e top-down (descendente). No processamento ascendente, o leitor ativa seu conhecimento linguístico e atribui significado à palavra. Neste processo, o leitor faz uso das informações que estão contidas no texto e faz uso da leitura das entrelinhas. Gomes $(2004$, p.6) acrescenta que, nesse modelo, o leitor tem um papel passivo, pois cabe a ele

“decodificar as unidades linguísticas e construir o significado do texto, partindo das unidades menores (letras e palavras) para as maiores". No que tange ao processamento descendente, o leitor faz uso intensivo e dedutivo de informações utilizando seu conhecimento de mundo para fazer previsões do que vai encontrar no texto (KATO, 1999).

Além desses dois modelos básicos de processamento de informação, podemos destacar também o modelo interacional. No modelo interacional, o leitor faz uso de dois tipos de conhecimento: o sistêmico e o esquemático. O sistêmico é tudo aquilo que corresponde ao conhecimento de mundo do leitor em relação ao texto. O esquemático refere-se ao conhecimento que o leitor já possui acerca dos diferentes tipos de textos, e também das relações 
entre frases e orações (GOMES, 2004). A autora resume que a leitura é delineada da seguinte maneira:

o sentido ascendente, cuja compreensão parte do texto ou dos signos verbais e não-verbais contidos no texto; o sentindo descendente, que considera o conhecimento do leitor como fonte importante de entendimento, e o sentido interacional, que contempla os outros dois, ou seja, ele é o resultado da interação contínua entre leitor e texto. O fluxo de informação passa a ser considerado bidirecional, isto é, ascendente e descendente ao mesmo tempo. (GOMES, 2004, p.6)

Gomes (2004) destaca que o modelo interacional de leitura tem função importante para o aprendiz de língua estrangeira, pois é através dele que o estudante precisará lidar com vocábulos desconhecidos e deverá selecionar informações e compilá-las com seu conhecimento de mundo para realizar associações para a compreensão dos textos.

No processo de ensino da habilidade de leitura existe um recurso chamado estratégia de leitura que é utilizado como um facilitador da compreensão textual. Sobre esse recurso, Kleiman (2012, p.74) salienta que as estratégias de leitura podem ser definidas como "operações regulares para abordar o texto". Mas como tomamos conhecimento dessas estratégias? Para Solé (1998) as estratégias de leitura são procedimentos de ensino e é preciso que sejam ensinadas, pois elas não se desenvolvem e nem aparecem instantaneamente. Ou seja, as estratégias de leitura precisam ser ensinadas e trabalhadas no contexto de sala de aula para que os estudantes saibam utilizar as estratégias de forma adequada.

Paiva (2010) afirma que as estratégias de leitura mais citadas pelos estudiosos da habilidade de leitura são: scanning e skimming. Segundo a autora, scanning é dar uma lida rápida, folhear, para achar algo específico. Complementando, Gomes (2004) menciona que essa busca específica pode ser um nome ou uma data. Já skimming é o ato de fazer uma leitura rápida para entender as ideias e conceitos principais; e, nesse caso, o leitor recorre ao título, subtítulo, autor, início e final dos parágrafos, palavras em itálicos e sumários.

Paiva (2010) ressalta que existem algumas outras estratégias que podem auxiliar no processo e desenvolvimento da leitura, entre elas: usar a inferência, usar conhecimento sobre formação de palavras, conhecer a organização textual e os conectivos, usar dicionário, verbetes e glossários, fazer marcas ou anotações no texto; formular hipóteses. Seguindo essa mesma diretriz, Gomes (2004) menciona que um leitor proficiente faz uso de todos os recursos disponíveis para a compreensão do texto. Contudo, para que o leitor seja capaz de fazer isso, é 
necessário que alguém o ensine a utilizar essas ferramentas para a compreensão do texto. Neste sentido, é fundamental que se trabalhe as estratégias de leitura em sala de aula.

As estratégias de leitura são mecanismos que nos possibilitam maior eficácia na habilidade de leitura. Com base nisso, constatamos que, se o aluno souber reconhecê-las e usálas, ele passará a entender melhor os textos, visto que, quando sentisse alguma dificuldade, procuraria alguma estratégia que pudesse auxiliar o processo de leitura. Sendo assim, este trabalho reforça a ideia de que as estratégias de leitura sejam ensinadas no espaço escolar para que o processo de ensino-aprendizagem de língua inglesa tenha melhora significativa no espaço escolar.

\section{Aspectos metodológicos da pesquisa}

Essa pesquisa se enquadra nos moldes da pesquisa qualitativa de base descritiva e interpretativista. Como mencionado anteriormente, nesse estudo apresentamos uma análise das atividades de leituras presente no livro didático de língua inglesa com o propósito de verificar se essas atividades utilizam as estratégias de leitura.

O nosso corpus de pesquisa foi retirado do livro High up. Optamos por esse livro, pois ele é adotado pela rede pública de ensino do Estado do Rio de Janeiro e por ter sido aprovado pelo Programa Nacional do Livro Didático (PNLD) de 2015. No que diz respeito à coleção do High up, ela é constituída por três volumes e cada um contém oito unidades. Para essa análise, focamos no volume três da coleção, que é destinado aos alunos do terceiro ano do ensino médio. Escolhemos analisar o último volume da coleção, pois é destinado aos alunos que estão terminando o ensino médio e, esses alunos, se entrarem em uma universidade, farão uso da língua inglesa e precisarão ter conhecimentos práticos acerca da leitura em inglês.

O terceiro volume da obra supracitada, selecionado para essa pesquisa, contém oito unidades e duzentas e dezoito páginas. Por se tratar de um material destinado a adolescentes, os temas das unidades se relacionam com procura de emprego, cuidados com a saúde, amigos, além de temas que são do interesse do público dessa faixa etária, como, por exemplo, vida online, relacionamentos amorosos, entre outros. As unidades são divididas em seções, e cada seção possui um foco e/ou um objetivo linguístico. As seções são divididas da seguinte maneira:

- Have your say: o objetivo é ativar os conhecimentos prévios dos alunos acerca do tema proposto na unidade;

- Reading beyond the words: o foco é trabalhar a habilidade de leitura e pós-leitura; 
- Genre analysis: o propósito é abordar as características do gênero trabalhado;

- Vocabulary: abarca tarefas com o objetivo de desenvolver o vocabulário a partir do texto lido;

- Grammar: o objetivo é trabalhar a gramática da LI;

- In other words: engloba explicações sobre os aspectos gramaticais dos gêneros textuais abordados;

- Practice makes perfect: o foco é praticar o conteúdo gramatical trabalhado na unidade;

- The way it sounds: a finalidade é trabalhar a compreensão oral;

- Talkactive: a intenção é desenvolver a fala do aluno;

- Self-assessment: contém uma autoavaliação da aprendizagem;

- Going beyond: possui sugestões de material e atividades para desenvolver a autonomia do aluno;

- Put it in writing: o objetivo é trabalhar a produção escrita. Esta seção é oferecida apenas nas unidades pares.

Cabe aqui mencionar que ao final de cada duas unidades, encontram-se também as seções Spot your talent, que possui informações sobre diversas profissões, e Self-study, que contém exercícios de consolidação da aprendizagem. Ademais, ao final do livro estão seções que complementam as unidades, contribuindo, assim, para o processo de aprendizagem da língua inglesa, são elas: Simulados do ENEM, Engage, Glossary, Irregular Verbs, Audio Scripts, Referências de sites, Referências bibliográficas, Self-study e Answer Key.

Para o presente estudo, selecionamos a seção Reading beyond the words de cada capítulo do livro High up, volume três, pois essa parte tem por propósito trabalhar/desenvolver a habilidade de leitura.

Para nortear nossa análise partimos das seguintes perguntas de pesquisa: 1) Há abordagem das estratégias de leitura?; 2) As atividades propostas são para explorar a habilidade de leitura em si?; 3) As atividades estão centradas no desenvolvimento de outras habilidades?

\section{Análise das atividades de leitura}


Na primeira unidade, é trabalhado o gênero textual piada levando o aluno a refletir sobre esse gênero. O material apresenta quatro piadas diferentes. No que concerne às atividades de leitura, elas são simples e não muito exploradas pelo livro didático, e, em sua maioria, são de assinalar com " $x$ " a resposta correta, não possibilitando ao aluno desenvolver suas respostas e nem sua reflexão acerca do gênero em questão.

No que tange às estratégias de leitura, as imagens da carinha feliz desenhada na parte superior do texto e do palhaço rindo na nota de um dólar, que acompanham as piadas, servem como base para inferência. Nesse caso, o professor pode explorar o gênero e levar o aluno a inferir o vocabulário que é apresentado. A exploração do vocabulário junto com as imagens antes da leitura ajudará os alunos a apreenderem o novo vocabulário e não a sentirem tanta dificuldade na realização dos exercícios propostos. Pode-se afirmar, assim, que a atividade de leitura proposta possibilita o uso de estratégias de leitura.

Na segunda unidade, a proposta de atividade é baseada no gênero anúncio publicitário. Antes da atividade e da exposição dos anúncios, é apresentado um verbete. O verbete é utilizado como uma estratégia de leitura.

A primeira atividade, da segunda unidade, faz uso de estratégias de leitura como: skimming e scanning, ao pedir que o aluno observe as imagens dos anúncios. Ademais, tem por objetivo sondar o conhecimento de mundo do aluno sobre o gênero em si. A atividade ainda propõe uma discussão entre os colegas de classe. Ainda na unidade 2, na terceira atividade de leitura, é proposto que os alunos trabalhem em duplas. Essa atividade levará os alunos a ativarem e compartilharem seus conhecimentos sobre o gênero textual e sobre os temas dos anúncios.

Na unidade três, a contextualização da atividade se dá através da pergunta que é proposta como pré-leitura. Essa pergunta (O que você espera encontrar em um texto sobre jogar lixo no lugar errado?) faz parte da atividade e é uma estratégia de leitura, visto que propõe ao aluno fazer previsões do que está por vir no texto. Inclusive, nesse momento, é relevante que o professor destaque para os alunos a importância de fazer previsões antes de realizar a leitura do texto. Essa unidade possui nove questões relacionadas ao texto; porém, nem todas estão voltadas à habilidade de leitura em si, algumas têm como objetivo trabalhar o conteúdo gramatical.

Na segunda proposta de atividade dessa unidade, corresponde a uma atividade de compreensão textual. É uma atividade simples e de assinalar a resposta correta. Para realizá-la, o estudante não faz uso das estratégias de leitura. Já a atividade três, ainda na terceira unidade, 
tem por objetivo coletar informações específicas do texto e nela podem ser usadas as estratégias scanning e skimming. Além disso, o aluno estaria usando os cognatos, conhecimentos do gênero textual e o uso de vocabulários.

As atividades quatro e cinco, não são para trabalhar a habilidade de leitura propriamente dita. Porém, nessas atividades o aluno poderia utilizar seus conhecimentos lexicais acerca do que foi proposto. Podemos observar que as questões sete e oito são questões de compreensão textual; porém, a questão sete tem o propósito de revisar um conteúdo gramatical que foi visto anteriormente pelos alunos, que é o uso do modal should. Já a questão oito é de interpretação, e dá ao aluno a chance de expor sua opinião sobre o tema. A questão nove é composta por duas perguntas pessoais e propõe uma discussão com o colega de classe. É notória a tentativa de aproximação da realidade do aluno na questão nove, letra a.

$\mathrm{Na}$ unidade quatro, a proposta de leitura é baseada no gênero blogger. Durante as atividades, os alunos fazem uso de inferência, scanning e skimming. Para a primeira questão, os alunos fazem inferências a partir da imagem. O exercício propõe uma discussão em classe que serve também como suporte de aprendizagem, visto que, nesse momento de efetuação da atividade, os alunos compartilham seus conhecimentos de mundo. Essa troca de saberes faz com que os alunos agreguem outros conhecimentos e que tenham mais facilidade na leitura.

Da questão dois até a questão sete, os alunos fazem uso de duas estratégias: scanning e skimming. Os alunos, nesse momento, retomam o texto em busca de determinadas informações, e, claro, não precisam reler o texto, pois as estratégias servem como suporte para o desenvolvimento destas questões. A questão oito traz perguntas relacionadas ao tema do texto; no entanto, são ainda perguntas que pressupõem respostas aleatórias, não necessariamente contidas no texto, mas que estejam motivadas por ele.

$\mathrm{Na}$ unidade cinco, a seção Reading beyond the words trabalha com dois gêneros distintos: um infográfico acompanhado de um trecho de artigo, e um poema. O que era tema de poemas, o amor romântico, agora é assunto em pesquisas cientificas, ou seja, nesta unidade, é feito um trabalho interdisciplinar, pois aborda também questões relacionadas à Biologia.

A primeira atividade proposta já nos sugere o uso das estratégias; ao passo que a atividade recomenda que o aluno "dê uma olhada" no infográfico. Esta frase sugere o uso das habilidades scanning e skimming. Além disso, pode-se fazer inferências a partir dos elementos extralinguísticos, como por exemplo, as imagens que estão disponíveis no texto.

Na questão dois, é pedido ao aluno que complete as frases com informações do texto. Nessa questão aluno faz uso da estratégia de leitura scanning, pois volta ao texto para uma leitura rápida com um objetivo específico. As questões três e quatro são de interpretação do 
texto. Neste caso, as estratégias de leitura já teriam que ter sido utilizadas para o aluno compreender o texto.

Assim como as questões três e quatro, a questão cinco também é de interpretação do texto, já na questão seis é proposto que o aluno faça uma pesquisa sobre o autor Wystan Hugh Auden. Essa pesquisa é uma atividade de pré-leitura, e, através dela, podemos fazer inferências sobre o gênero textual que será abordado posteriormente.

A atividade sete não explora o uso de estratégias de leitura, é uma simples de interpretação de texto na qual o aluno terá que assinalar a resposta correta.Na questão oito, também é possível fazer uso de uma estratégia de leitura. Nesta atividade, é pedido que os alunos sublinhem cinco palavras do poema que eles não conhecem do poema e que as procurem em um dicionário. $\mathrm{O}$ ato de procurar essas palavras faz parte de uma estratégia de leitura; além disso, o aluno estaria agregando novo conhecimento lexical.

$\mathrm{Na}$ atividade nove são usadas as estratégias de leitura, visto que os alunos retornam ao texto com um objetivo específico que é proposto em cada alternativa da questão. Por fim, a questão dez não utiliza as estratégias de leitura; é uma questão de interpretação de textos.

Na unidade seis, a seção Reading beyond the words é um pouco mais extensa do que nas outras unidades. Notamos que a questão um propõe que o aluno faça uso da inferência com base na leitura do título do texto para deduzir qual assunto será abordado. Na atividade dois, pede-se ao aluno que seja feita uma leitura rápida do primeiro parágrafo, fazendo assim o uso de uma estratégia de leitura: skimming.

Na terceira atividade, também enfoca-se o uso da inferência, visto que é pedido ao aluno que pense sobre o que ele acredita que vai acontecer na continuação da história. $\mathrm{Na}$ atividade quatro, é apresentada a continuação da história e pede-se que o aluno cheque sua previsão na atividade três. A quinta atividade é para colocar os fatos na ordem em que eles aconteceram na história. Nesta atividade, não é solicitado o uso de estratégias; porém, ao retornar o texto em busca dos fatos, os alunos estariam reforçando duas estratégias já utilizadas: scanning e skimming .

A atividade seis é uma atividade simples na qual é proposta a leitura do capítulo três do texto e são formuladas duas perguntas sobre este capítulo. Para responder essas perguntas, os alunos poderão recorrer ao uso das estratégias de leitura: scanning e skimming. A atividade sete é uma pergunta relacionada ao texto, mas não possibilita o uso de estratégias de leitura, porque a resposta é de cunho pessoal.

A atividade oito tem a mesma característica da atividade três, que é fazer o uso de inferências e prever o que vai acontecer no desenrolar da história. E a atividade nove pede 
apenas para que o aluno leia o texto e verifique se sua inferência acerca do texto está correta ou não. A atividade dez também trabalha com a inferência, pede-se que o aluno leia o título do último capitulo e deduza o vocabulário que será apresentado. A última questão dessa seção propõe uma discussão em sala sobre o tema que é explorado durante o texto, a saber: a violência contra mulher. São perguntas pessoais para que os alunos possam expor suas opiniões, além disso, a proposta dessa atividade é não apenas trabalhar o conteúdo de língua inglesa, mas também abordar questões sociais, direitos humanos e as relações de gêneros.

Na unidade sete, o gênero a ser trabalhado nesta unidade é o cartoon. Na atividade um, os alunos poderão utilizar as imagens para inferir o tema dos cartoons e responder as questões propostas. Para a realização da atividade dois, não é necessário fazer uso das estratégias de leitura, visto que é uma tarefa que requer apenas a reflexão sobre as atitudes salientadas nos cartoons. Nas questões três, quatro e seis, os alunos poderão usar as seguintes estratégias: scanning e skimming para responder as perguntas, visto que eles retornarão ao texto com um propósito específico. Para responder a questão cinco, o aprendiz não precisará recorrer a nenhuma estratégia de leitura, pois o tema de cada cartoon terá sido abordado nas questões anteriores.

Notamos que nas atividades oito e nove não é possível usar as estratégias de leitura, visto que a questão oito é uma atividade que possibilita respostas aleatórias relacionadas ao tema da unidade e a questão nove tem por objetivo promover um debate em sala de aula sobre o tema. Na questão sete, onde também é trabalhada a habilidade de leitura, ao classificar as sentenças em verdadeiras ou falsas, o aluno recorrerá ao texto, fazendo uso das seguintes estratégias: scanning e skimming .

Na unidade oito, última unidade desse do volume três, a seção Reading beyond the words inicia-se com três atividades que podem ser destacadas pelo professor na escola como atividades de pré-leitura. A primeira é sobre William Shakespeare com três questões sobre a vida do autor. A questão dois é sobre a popularidade do autor. Para estas duas questões, é necessário que o aluno faça uma pesquisa sobre o autor antes de responder. A questão três é uma atividade de compreensão auditiva e leitura. Na verdade, o foco é a compreensão auditiva do monólogo. Para estas atividades, o aluno não poderá recorrer ao uso das estratégias de leitura.

Podemos notar que a atividade quatro também usa o monólogo como uma atividade de compreensão auditiva; porém, neste caso, existem fatores extralinguísticos (as imagens), que podem ser usados para inferência, e que colaboram para a compreensão auditiva e leitura do monólogo. A questão cinco aborda exatamente as imagens que estão presentes no monólogo, 
pedindo para que o aluno explicite o que elas estão representando. Essa atividade faz com que o aluno possa inferir o sentindo do monólogo.

As questões seis, sete e oito trabalham com interpretação textual, e, para responder essas perguntas, os alunos poderão utilizar as estratégias de leitura. Poderão fazer inferências através das imagens e do conteúdo lexical, poderão também usar as estratégias scanning e skimming. Na questão nove, o aluno não fará uso das estratégias, pois é uma pergunta de cunho pessoal. Para este tipo de questão não se usa as estratégias de leitura.

\section{Considerações finais}

Conforme foi apresentado ao longo desse artigo, a habilidade de leitura constitui um elemento muito importante para a formação do aluno, permitindo a ele acesso as mais variadas formas de culturas e saberes na língua alvo. No âmbito da educação, é importante que o ensino da habilidade de leitura seja feita de forma crítica e reflexiva, possibilitando assim, um ensino de língua inglesa atrativo, motivante e eficaz.

Com o intuito de formar alunos fluentes na língua inglesa muitas metodologias foram surgindo e, com isso, o ensino focado na habilidade oral da língua passou a ser prioridade em muitos materiais didáticos. Como resultado, a leitura passou a ser deixada de lado, e os textos passaram a ser utilizados para trabalhar outros conteúdos e não a leitura em si.

Através deste trabalho, procuramos analisar as atividades de leitura propostas no livro High up, que é usado pela rede pública de ensino do Rio de Janeiro. Nessa análise, procuramos salientar quais propostas de atividades estavam trabalhando a habilidade de leitura e quais estavam usando o texto para trabalhar outras habilidades. Procuramos mostrar, também, que a ativação do conhecimento prévio do aluno e de suas estratégias como ferramentas de aprendizagem podem contribuir para o ensino-aprendizagem de língua inglesa e para uma maior compreensão dos textos disponibilizados no material didático.

Ao longo da análise das atividades selecionadas, podemos observar que o livro High up, de um modo geral, possui atividades de leitura que contemplam a habilidade em si e que trabalham com as estratégias de leitura propriamente ditas. Constatamos que o gênero textual mais adotado nas atividades de leitura foi o poema e que as estratégias que predominaram nas atividades foram scanning e skimming.

Este trabalho nos possibilitou perceber que, em parte, algumas atividades de leitura dos livros didáticos não trabalham explicitamente as estratégias de leitura. Um aspecto positivo 
a se considerar é que o livro analisado trabalha com diversos gêneros textuais, possibilitando, assim, que os alunos tenham contato com os gêneros e aprendam suas características e saibam como utilizá-los.

Ademais, constatamos que as atividades de leitura precisam ser mais exploradas para que o ensino dessa habilidade seja feito de maneira eficaz, e que as estratégias de leitura precisam ser ensinadas explicitamente durante as aulas. É interessante para o aluno saber quais recursos utilizar diante de um texto mesmo que estes recursos não sejam propostos pelas atividades. Sendo assim, sugere-se que as estratégias de leitura sejam trabalhadas paralelamente às atividades propostas pelo material didático para que possa tornar eficaz o ensinoaprendizagem de língua inglesa no âmbito da escola pública.

\section{Referências bibliográficas:}

AMORIM, M. L. V. Ensinando Leitura na Sala de Aula de Inglês: Teoria e Prática. In: TADDEI, E. (Ed) (1997) Perspectivas: O ensino da Língua Estrangeira. SME. Rio de Janeiro.

BRASIL MEC/SEB. Parâmetros Curriculares para o Ensino Médio, 4 volumes. Brasília, 2000.

BRETON, J. M. Reflexões anglófilas sobre a geopolítica do inglês. In: LACOSTE, Y (Org.). A geopolítica do inglês. São Paulo: Parábola Editorial, 2005.

CANTALICE, L. M.. Ensino de estratégias de leitura. Psicol. Esc. Educ. (Impr.), Campinas, v. 8, n. 1, p. 105-106, Jun 2004.

CARMAGNANI, A. M. A contribuição do ensino de leitura em língua estrangeira na escola de $1^{\circ}$ e $2^{\circ}$ Graus. Perspectiva 4.8 (1987), p. 52-58.

Relendo modos de ler a leitura. Contexturas: Ensino crítico de língua inglesa, São Paulo 1.1 (1992): 33-40.

DIAS, R; JUCÁ, L; FARIA, R. High up: ensino médio. Cótia, SP: Macmillan, 2013. 
FREIRE, P. A importância do ato de ler: em três artigos que se completam. São Paulo: Cortez, 2006.

GARCEZ. L. H. do C. Técnica de redação: o que é preciso saber para bem escrever. São Paulo: Martins Fontes, 2001

GOMES, A. M. C. A compreensão da metáfora na leitura de texto promocionais em língua estrangeira. Dissertação de Mestrado. UFF, 2004

GOODMAN, K. The reading process. In: CARREL, P. L.; DEVINE, J.; ESKEY, D. E. (Eds.). Interactive approaches to second language reading. Cambridge: CUP, 1998. p. 11-21.

JOUVE, V. A leitura. São Paulo: Unesp, 2002. Trad. Brigitte Hervot.

KATO, M. A. O aprendizado de leitura. 5. ed. São Paulo: Martins Fontes, 1999.

KLEIMAN, A. Leitura: ensino e pesquisa. Campinas, SP: Pontes, 1989. Texto e Leitor: Aspectos Cognitivos da Leitura. $4^{\text {a }}$ Edição. Campinas, SP:

Pontes, 1995. Oficina de leitura - teoria e prática. Campinas, SP: Pontes Editores, 2012.

MOITA LOPES, L. P. Oficina de linguística aplicada: a natureza social e educacional dos processos de ensino/aprendizagem de línguas. Campinas: Mercado de Letras, 1996.

NUTTALL, C. Teaching reading skills in a foreign language. 2. ed. Oxford: Heinemann, 1996.

PAIVA, V. L. M. O. Práticas de ensino e aprendizagem de inglês com foco na autonomia.

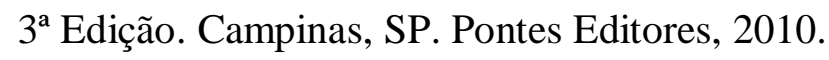

RAJAGOPALAN, K. Por uma linguística crítica: linguagem, identidade e a questão ética. São Paulo: Parábola, 2003.

SOLÉ, I. Estratégias de leitura. 6. ed., Porto Alegre: Artmed, 1998.

WALLACE, C. Reading. Oxford: OUP, 1992. 